\title{
End of life in chile: what can we learn from death cafes?
}

Keywords: death; attitude to death, death education, death café, end of life, community education

\section{Introduction}

A first and yet preliminary experience of Death Cafes started in Chile in November 2016 Despite no conclusions can be obtained yet, it is nevertheless of interest to discuss its topics, reasons and goals. As in many other Latin American countries and other world regions, deep demographic changes are occurring nowadays, together with a high increase in complex and high cost medical treatment at end of life in this context, the fact to be able to talk about death becomes a social need. In this article, we aim to bring up this subject as well as share our experience Death Cafe in Santiago, Chile.

Chile is experiencing a fast demographic transition. An increase in the number of people aged 65 and over is expected to double in the next 20 year. ${ }^{1}$ It is predicted that by $2030,16.5 \%$ of the population will be older adults ( $>65$ years) and that there will be 8.5 deaths every year per 1000 people. $^{2}$ This demographic configuration is similar to the 2016 figures in UK and US $(17.9 \%$ and $15.2 \%$ of adults $>65$ years respectively). ${ }^{3}$ From the health system perspective, this represents one of the main health challenges for the next decades. Healthcare needs at end of life are particularly complex. Hence, with almost no longterm care options or hospices covered by the Social Health Insurance as it is now, deep health service reorganization seems unavoidable.

Death is a culturally attached human process. Reflections on death bring us to almost all of the greatest thinkers, such as Socrates, Epicurus, Hegel and Albert Camus. Religions have tried to offer a concrete response to this question by studying and arguing about the afterlife. Moreover, science has defined it as the cessation of biological functions. Nonetheless, death is usually faced from several viewpoints, depending on experience, fears, and perceptions that differ from person to person, place to place and time to time. In the end, to think and to talk about death implies to do it about life, the meaning of our existence, whom we are and how we face our lives.

Therefore, to have a better understanding about death becomes fundamental, especially if we aim to design culturally appropriate end of life care policies. Do our predefined conceptions of death match with what people in our community belief? Why do patients with advanced diseases and their families are so often ill prepared for what is inevitable? Are medical doctors prepared to face their patient's death? These questions, among others, need to be discussed in our societies and open social reunions are good opportunities for this.

Death Cafes started with the Café Mortel movement in Switzerland in the early 2000s. Bernard Crettaz, who organised these gatherings, aimed to break the "tyrannical secrecy" around death. ${ }^{4} \mathrm{He}$ acknowledged that in the modern western world to talk about death is not easy, but not less relevant. In the UK a former council worker, Jon Underwood, organized the first event in London in 2012. The huge public interest on these Cafes resulted in the social franchise Deathcafe.com, ${ }^{5}$ a web-page where events, news and instructions to organize these meetings are available. Underwood died in 2017, yet
Volume I Issue 4 - 2017

\author{
Browne J,' Reeves $\mathrm{M}^{2}$ Beca JP3 \\ 'Centro de Geriatría y Gerontología, Pontificia Universidad \\ Católica de Chile, Chile \\ 2 MSc in Philosophy and Public Policy, LSE, Public Education \\ Advisor, Ministry of Education, Chile \\ ${ }^{3}$ Centro de Bioética, Facultad de Medicina, Clínica Alemana \\ Universidad del Desarrollo, Chile
}

Correspondence: Juan Pablo Beca, Centro de Bioética, Facultad de Medicina Clínica Alemana Universidad del Desarrollo, Chile, Email jpbeca@udd.cl

Received: August 29, 2017| Published: September 12, 2017

his legacy is more alive than ever. Today Death Cafes are constantly organized around the world attracting public and media to talk freely about death. However, in Latin America these reunions are being organized very recently.

The Chilean Death Cafe experience started in 2016 as monthly open meetings. With no previous similar events organized in Chile before, we relied on Deathcafe.com franchised. Anybody who is interested in taking about death is invited to sign up for an event without restrictions of age, motives or background. In the absence of an agenda or planned objectives, we meet in a public restaurant for an honest, respectful and friendly conversation. As described in previous experiences abroad, the discussions have gone fluent without exceptions. Cultural adaptations were indeed made: a glass of red wine and a pizza slice instead of coffee and cake are offered. Since we started tintos de la muerte (so called for the red wine) they have become a monthly "death coffee meetings", being followed by other groups that have organized similar events in Chile, helping to raise the awareness about death.

Tintos de la muerte are not meant to be a space to collect representative data on perceptions of death in Chile. Hence, in this article, we describe a preliminary result of personal interpretations of these social gatherings where more than 80 people have participated. Still, remarkable topics have been raised, which are important to share. Differently from what we anticipated, pain and disease have not been the most frequent personal concerns around death. What have been raised repeatedly are loneliness, the idea of being forced to receive medical treatments against their will, and the liberty for deciding how, where and when to die, including euthanasia and suicide.

\section{Over-medicalisation or under-socialisation?}

Statements such as "unnecessary prolongation of life" and to be "dependent on machines" are frequently heard during our meetings. Hospitals and especially intensive care units are perceived as inadequate places to die, but why? In these settings the loss of control of personal decisions, and the fact of modifying the natural course of death are frequently expressed as main concerns. Nevertheless, 
those who have accompanied others during their end of life period do recognize the complexity of care-giving and the feeling of being unsupported while caring for a dying person at home. Moreover, older people have mentioned that they do not want to transfer all the personal and financial responsibilities to their family members. This shows the difficulty of handling the process of death, where feelings about over medicalisation of death are confronted with the benefits, complexity and burden of care management. Also, when asked, few participants knew or had written some kind of advanced directives. These documents serve as a mechanism to preserve the values and preferences of a person at the end of his or her life. Living wills may help to prevent the loss of control and to accept the natural course of death caused by non-treatable disease. Still, they are largely underused, which is somehow peculiar given our previously described fears of a medicalised and uncontrolled death.

The lack of conversations regarding death can limit the scarce use of oral or written advance directives. Almost every participant in tintos de la muerte meetings has mentioned the difficulties they encounter when trying to talk about death with others, especially when the ill ones are their partners, friends, parents or children. There are those who have shared their regrets of not having ever been able to talk about death during their whole process of illness. This tension seems strange under the Latin American stereotype of close family relationships, but indeed it does happen. Even experienced health professionals have shared their uneasy feeling when talking about death with their patients, colleagues and their own families. Participants agree that avoidance of these conversations is usually a way of coping with this tension. As a result, few people do know what really matters to their loved ones at their end of life.

To talk about death has a value by its own. Culturally appropriate policies to improve how we face the end of life, need to start with open discussions of how and where we want to spend the ending of our lives. Yet, it is difficult to have that discussion if we do not talk about it at all, even with our close ones. Increasing the awareness and "socializing" death should, therefore, have a positive impact in the death experience and in shaping better end of life health care policies. For the demographic trend that is ahead of us, denial of death and prolongation of life support of terminal patients do not seem to be reasonable options. When possible, people deserve to have a peaceful death. This responsibility does not only rely on health services, but also on all of us as a society trying to fulfill our personal and our loved ones' perceptions of what is a good death.

\section{Conclusion}

We consider that social open discussions about death are a social need in our contemporary societies to improve end of life care together with palliative care strategies. The role of Death Cafes and other similar efforts appear to be a valuable contribution to this end.

\section{Acknowledgements}

None.

\section{Conflict of interest}

The author declares no conflict of interest.

\section{References}

1. Lee M, Scommegna P. Aging in Latin America and the Caribbean, Washington, USA. Population Reference Bureau. 2014. p. 1-10.

2. Instituto nacional de estadística. Proyecciones y Estimaciones de Población. Total país período de información: 1950-2050, Santiago, Chile: Springer; 2005.

3. http://stats.oecd.org/Index.aspx?DataSetCode=HEALTH_DEMR

4. https://www.theguardian.com/lifeandstyle/2014/mar/22/death-cafe-talkabout-dying

5. http://deathcafe.com/ 